Fourth International Conference on Sustainable Construction Materials and Technologies http://www.claisse.info/Proceedings.htm

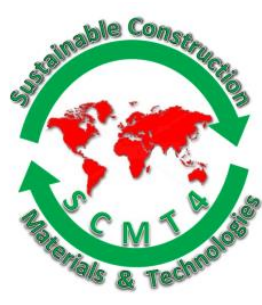

SCMT4

Las Vegas, USA, August 7-11, 2016

\title{
Improving Properties of Recycled Concrete Aggregates by Accelerated Carbonation
}

\author{
Zengfeng Zhao*1a, 2a, Sébastien Remond ${ }^{2 b}$, Denis DamidotA ${ }^{2 c}$, Luc Courard ${ }^{1 b}$, \\ and Frédéric Michel ${ }^{1 \mathrm{c}}$
}

${ }^{l}$ ArGEnCo Department, GeMMe Building Materials, University of Liège, Belgium, ${ }^{\text {la Email: }}$ <zengfeng.zhao@ulg.ac.be>, ${ }^{1 b}$ Email:<luc.courard@ulg.ac.be>, ${ }^{l c}$ Email: 〈frederic.michel@ulg.ac.be>.

${ }^{2}$ Civil and Environmental Engineering, Mines Douai, LGCgE GCE, Douai, France, ${ }^{2 b}$ Email: <sebastien.remond@mines-douai.fr>, ${ }^{2 c}$ Email:<denis.damidot@mines-douai.fr>.

\begin{abstract}
Large amounts of construction and demolition wastes, especially concrete wastes, are generated annually and will increase in the future. In the same time, very large quantities of natural aggregates are needed for the construction of roads, buildings or civil engineering infrastructures. Until now, only a small fraction of concrete wastes is re-used as recycled concrete aggregates (RCA) in the manufacture of mortar and concrete. In order to optimize the use of RCA for new concrete, it is important to improve the properties of RCA. RCA are mainly composed of an intimate mix between natural aggregates and adherent hardened cement paste. Hardened cement paste generally presents a much larger porosity than natural aggregates which induces that the physicochemical properties of RCA are largely influenced by it.
\end{abstract}

In this paper, the influence of the accelerated carbonation on the properties of RCA is studied. Original concrete was manufactured in the laboratory and then crushed by a jaw crusher in the laboratory. The different fractions of laboratory produced RCA were stored in the accelerated carbonation room. The mass loss measured by themogravimetric analysis, the density, the porosity and the water absorption of RCA were tested before and after carbonation. Industrial RCA was also studied for comparison with the laboratory produced RCA. Results clearly show that, after accelerated carbonation, the density of RCA increases, which is due to the transformation of portlandite into calcite. The water absorption and porosity of RCA both decrease after carbonation.

\section{INTRODUCTION}

Due to the growth of population and the rapid development of construction industry, large amounts of construction and demolition wastes are generated yearly in the world and theses quantities are expected to increase in the future. It is very important to recycle these wastes in order to protect the environment. Meanwhile, very large quantities of natural aggregates are needed for the construction industry. Until now, only a small fraction of concrete wastes is re-used as recycled concrete aggregates (RCA) in the manufacture of mortar and concrete [Poon et al. 2002]. In order to optimize the use of RCA for new concrete, it is important to improve the properties of RCA. RCA are mainly composed of an intimate mix 
between natural aggregates and hardened cement paste. The properties of RCA depend on lots of influence factors such as original concrete, contaminants, particle size, crushing method for production, and storage conditions. Hardened cement paste generally presents a much larger porosity than natural aggregates, the content and the physicochemical properties of hardened cement paste therefore have a large influence on the properties of RCA [Zhao et al. 2013, 2015].

As we all know, climate change and global warming is a huge international challenge now. In order to reduce the carbon emissions, it is very important to study the potential way to capture the $\mathrm{CO}_{2}$. Carbonation is a procedure where carbon dioxide $\left(\mathrm{CO}_{2}\right)$ in the atmosphere penetrates and diffuses through the pore water and reacts with calcium hydroxide $\left(\mathrm{Ca}(\mathrm{OH})_{2}\right)$, producing calcium carbonate $\left(\mathrm{CaCO}_{3}\right)$ and water. In addition, hydrated calcium silicate $(\mathrm{C}-\mathrm{S}-\mathrm{H})$ can also react with $\mathrm{CO}_{2}$ [Chang and Chen 2006]. Ngala and Page [Ngala and Page 1997] investigated the effect of carbonation on pore structure and diffusional properties of hydrated cement pastes. The results showed that the total porosity for all the studied pastes reduced after the carbonation. However, much less studies were dedicated to the influence of carbonation on the RCA.

In this paper, the possibility of improving the properties of RCA by accelerated carbonation is studied. Original concrete was manufactured in the laboratory and then crushed by a jaw crusher. The different fractions of laboratory produced RCA were stored in the accelerated carbonation room. The mass loss measured by themogravimetric analysis, the density, the porosity and the water absorption of RCA were tested before and after carbonation. Industrial RCA were also studied in order to compare with the laboratory produced RCA.

\section{MATERIALS AND METHODS}

\section{Materials}

Laboratory manufactured RCA. Original concrete was manufactured for production of recycled concrete aggregates (RCA). Table 1 shows the details of original concrete composition. The cement used in this study was a white OPC (CEM I 52.5 "superblanc") provided by Lafarge company. Crushed calcareous sand and calcareous coarse aggregates sourced from Tournai (provided by Holcim France Benelux) were used for production of original concrete. After 90 days curing in water, original concrete was crushed in the laboratory by using a jaw crusher with the opening size $(10 \mathrm{~mm})$. After crushing, RCA were dried in the oven at $105^{\circ} \mathrm{C}$. In this study the focus is on the fine recycled concrete aggregates (FRCA) $(0 / 5 \mathrm{~mm})$. FRCA was then separated by sieving in four different granular classes $(0 / 0.63$, $0.63 / 1.25,1.25 / 2.5,2.5 / 5 \mathrm{~mm}$ ) in order to study the influence of granular class on the properties of RCA. The four different granular classes of RCA were stored in seal bags in order to minimize carbonation (considering as noncarbonated RCA). In the following, each granular class is represented by its average particle size, corresponding to the average value of the minimal and maximal particle sizes of the granular class.

\section{Table 1.Original concrete composition made in the laboratory $\left(1 \mathrm{~m}^{3}\right)$}

\begin{tabular}{|c|c|c|c|c|c|c|}
\hline & $\begin{array}{c}\text { Cement } \\
(\mathrm{kg})\end{array}$ & $\begin{array}{c}\text { Coarse } \\
\text { aggregates }(\mathrm{kg})\end{array}$ & $\begin{array}{c}\text { Sands } \\
(\mathrm{kg})\end{array}$ & $\begin{array}{c}\text { Efficient } \\
\text { water }(\mathrm{kg})\end{array}$ & $\mathrm{W}_{\text {eff }} / \mathrm{C}$ & $\mathrm{fc}_{90}(\mathrm{MPa})$ \\
\hline Concrete & 298.8 & 1138.3 & 756.4 & 179.3 & 0.6 & 47 \\
\hline
\end{tabular}

The four different granular classes of RCA were then stored in a pure $\mathrm{CO}_{2}$ carbonation cell at $20^{\circ} \mathrm{C}$. Supersaturated $\mathrm{NaCl}$ solution was used to obtain a constant relative humidity of $75 \%$. After two weeks of accelerated carbonation, a solution of phenolphthalein was used as indicator to check the carbonation degree. It shows that, after carbonation, phenolphthalein does not turn pink; indicating that carbonation of the sample is almost complete at least at their surface (Figure1). All the granular classes of laboratory- 
manufactured-well-carbonated RCA (noted as RCAl_wc) and laboratory-manufactured-noncarbonated RCA (noted as RCAl_nc) were characterized including mass loss measured by themogravimetric analysis, density, porosity, and water absorption.

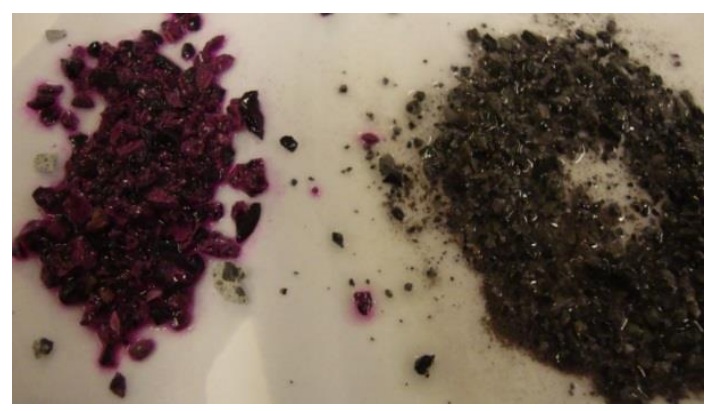

Figure 1. Carbonation tested by the solution of phenolphthalein (left: before carbonation; right: after carbonation)

\section{Industrial RCA}

RCA produced in industrial crushing platform were also used (noted as RCAi). RCAi was produced on the platform of Louvres (Colas). Only fraction 0/5mm of RCA was studied and they were subdivided into the four granular classes previously used for the RCA made in the laboratory. All the granular classes of industrial RCA were tested for the same properties as laboratory manufactured RCA.

\section{Experimental methods}

Thermogravimetric analysis. Representative samples of each granular class were pre-dried in the oven at a temperature of $105^{\circ} \mathrm{C}$. A sample powder was then obtained by grinding the material to a maximum size of $0.2 \mathrm{~mm}$, and a thermogravimetric analysis with analysis (TGA) of gas by mass spectrometry (MS) was then carried out using TGA NETZSCH STA449 F3. The heating was composed of three different phases:

- From ambient temperature to $105^{\circ} \mathrm{C}$ : heating rate of $2^{\circ} \mathrm{C} / \mathrm{min}$

- 30 mins at a constant temperature of $105^{\circ} \mathrm{C}$

- From 105 to $1100^{\circ} \mathrm{C}$ : heating rate of $3^{\circ} \mathrm{C} / \mathrm{min}$.

Density. For each RCA and each granular class, representative samples were pre-dried in the oven at a temperature of $105^{\circ} \mathrm{C}$, and then density was measured by using helium pycnometer (Micromeritics AccuPyc 1330).

Water absorption. The water absorption coefficient of each granular class of RCA was measured with the method $n^{\circ} 78$ of IFSTTAR [IFSTTAR 2011]. The samples were saturated 24 hours in water a (1) the water absorption coefficient was determined based on the water content at saturated surface dry (SSD) state. The aggregates were dried progressively with different sheets of colored absorbent paper until no trace of water can be seen on the paper noted as SSD mass $\left(M_{1}\right)$. The surface of each sheet of colored absorbent paper was wiped carefully with a brush to ensure that no fine particles remain attached on the paper. In that SSD state, no moisture remains at the surface of particles (third sheet of paper on Figure 2). The aggregates were then dried in an oven at $105^{\circ} \mathrm{C}$ to constant mass $\left(\mathrm{M}_{2}\right)$. The water absorption coefficient of RCA was then calculated according to Equation 1:

$W A=\frac{M_{1}-M_{2}}{M_{2}} \times 100$ 


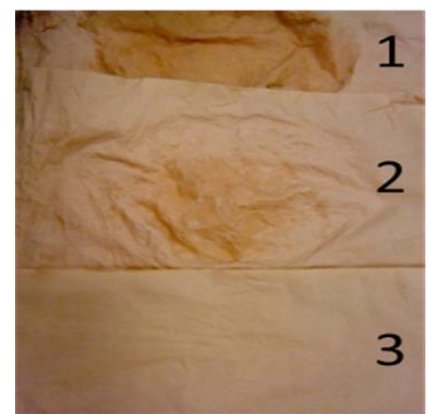

Figure 2. Trace of water after successive dryings with absorbent paper (IFSTTAR method)

Porosity. Fraction 2.5/5mm of RCAl_nc and RCAl_wc was tested by using Mercury Intrusion Porosimetry (MIP) technique with machine Micromeritics Autopore IV.

\section{RESULTS AND DISCUSSIONS}

TGA results with analysis of gas by mass spectrometry. Figure 3 and Figure 4 present the TGA results with analysis of gas by MS for RCAl_nc and RCAl_wc with fraction 1.25/2.5mm. In these figures, the peak at $150-175^{\circ} \mathrm{C}$ corresponds to a loss of water in C-S-H. The peak at $450^{\circ} \mathrm{C}$ corresponds to the loss of water in the portlandite (similar results are found in Alarcon-Ruiz et al. 2005; DeJong and Ulm 2007) which almost disappears after the carbonation meaning that the portlandite has transferred to calcite.

Figure 3 and Figure 4 first show that the loss of $\mathrm{CO}_{2}$ in uncarbonated samples is negligible for tempartures lower than $600^{\circ} \mathrm{C}$. This confirms that, in uncarbonated samples, the mass loss between 105 and $600^{\circ} \mathrm{C}\left(\mathrm{ML}_{105-600}\right)$ comes essentially from the departure of water. When the cement paste is not carbonated, the peak due from $\mathrm{CO} 2 / \mathrm{CO}$ is linked only to the decomposition of limestone aggregates and is located between 600 and $900^{\circ} \mathrm{C}$. However, for carbonated samples, when the cement paste is carbonated, decarbonation starts earlier (from $500^{\circ} \mathrm{C}$ ). Figure 4 clearly shows that part of the mass loss between 105 and $600^{\circ} \mathrm{C}$ comes from the departure of $\mathrm{CO}_{2}$.

Figure 5 presents the TGA results with analysis of gas by MS for RCAi with fraction $1.25 / 2.5 \mathrm{~mm}$. As can be seen in this figure, a large peak of mass loss is obtained between 500 and $850^{\circ} \mathrm{C}$ due to the departure of $\mathrm{CO}_{2}$ which suggest that RCAi contain calcareous aggregates. Moreover a significant decarbonation starts at $500^{\circ} \mathrm{C}, \mathrm{CO}_{2}$ loss from $500^{\circ} \mathrm{C}$ makes it possible to highlight the carbonation of the cement paste, thus it shows that the RCAi are partly carbonated.

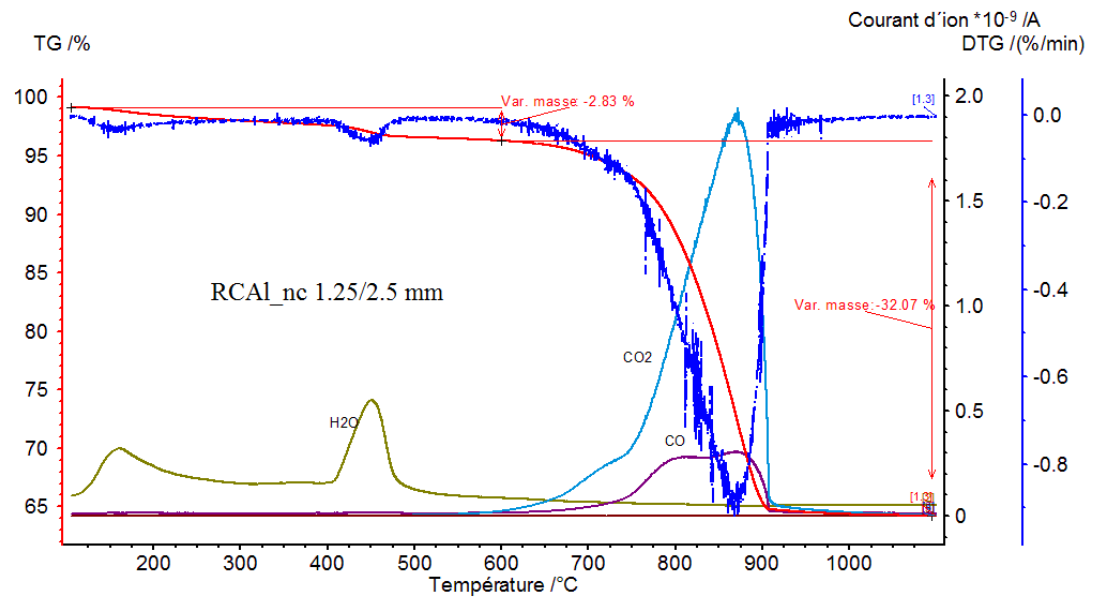

Figure 3. TGA with gas of RCAl_nc $1.25 / 2.5 \mathrm{~mm}$ 


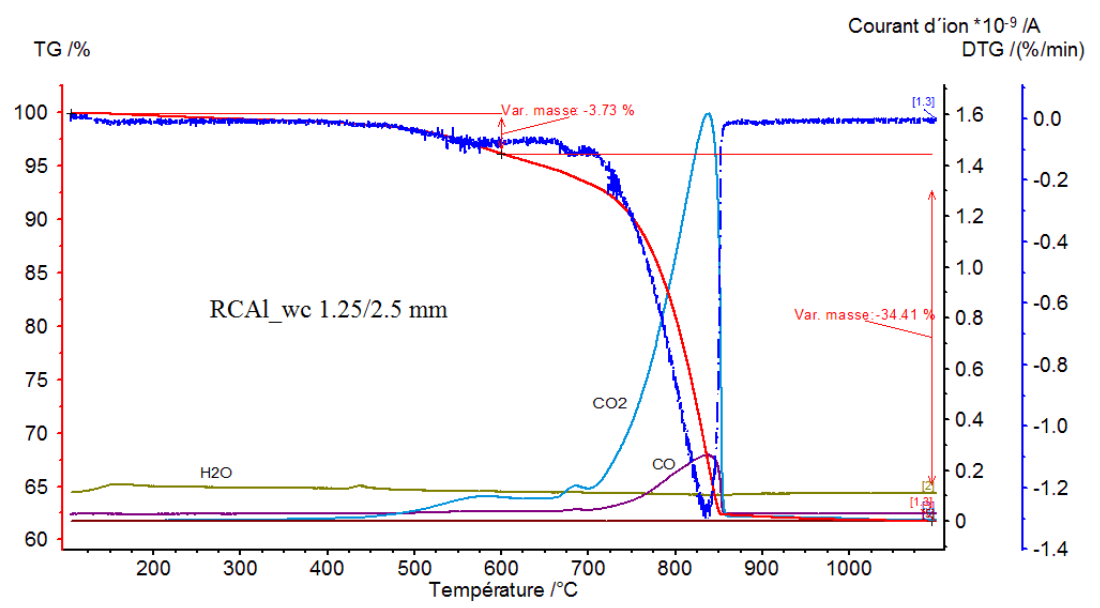

Figure 4. TGA with gas of RCAl_wc $1.25 / 2.5 \mathrm{~mm}$

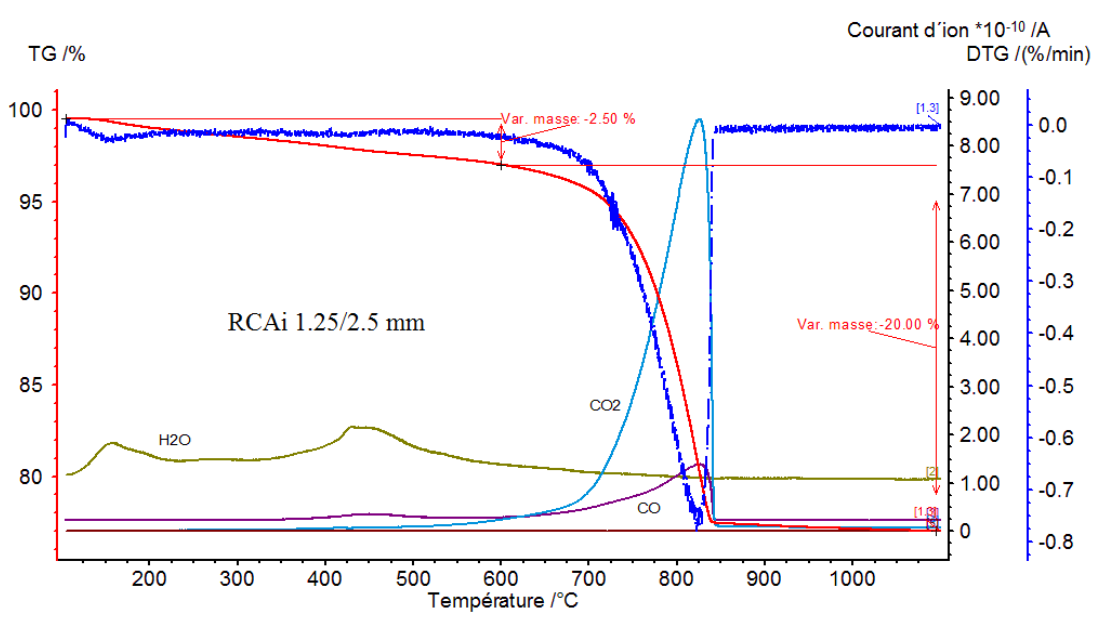

Figure 5. TGA with gas of RCAi $1.25 / 2.5 \mathrm{~mm}$

Table 2 shows the values of mass loss between 105 and $400^{\circ} \mathrm{C}\left(\mathrm{ML}_{105-400}\right)$, between 400 and $500^{\circ} \mathrm{C}$ $\left(\mathrm{ML}_{400-500}\right)$, between 500 and $600^{\circ} \mathrm{C}\left(\mathrm{ML}_{500-600}\right)$, between 600 and $700^{\circ} \mathrm{C}\left(\mathrm{ML}_{600-700}\right)$, and between 700 and $1095^{\circ} \mathrm{C}$ (ML M $_{700-1095}$ ) based on TGA with gas. For all studied RCA, the ML ${ }_{105-400}, \mathrm{ML}_{400-500}, \mathrm{ML}_{500-600}$, $\mathrm{ML}_{600-700}$ increase as the particle size of RCA decreases. ML ${ }_{700-1095}$ corresponds to the content of crystallized calcite in the sample. Therefore, the finer fraction of RCA contains higher quantity of portlandite, and the finer fraction of RCA has larger hardened cement paste content and also higher porosity comparing with the coarser fraction of RCA. As can be seen, after carbonation, $\mathrm{ML}_{400-500}$ decreases which is due to the transfer of portlandite to calcite leading to a lesser loss of water. ML400-500 corresponds partly to the water bounded by portlandite $\left(\mathrm{ML}_{\mathrm{H} 2 \mathrm{O}-400-500)}\right)$ and some decarbonation of amorphous calcite (ML $\mathrm{MO}_{\mathrm{CO}-400-500}$ ). However, in the same time, $\mathrm{ML}_{500-600}$ and $\mathrm{ML}_{600-700}$ increases after carbonation due to a significant departure of $\mathrm{CO}_{2}$ between 500 and $700^{\circ} \mathrm{C}$. This suggests that the formation of amorphous carbonation products occurred during our accelerated carbonation tests (confirmed by Thiery et al. 2007; Villain et al. 2007).

From the curves of gas by MS, the surface areas of $\mathrm{H}_{2} \mathrm{O}\left(\mathrm{S}_{\mathrm{H} 2 \mathrm{O}}\right)$ and $\mathrm{CO}_{2}\left(\mathrm{~S}_{\mathrm{CO} 2}\right)$ could be estimated, then the mass ratio of $\mathrm{H}_{2} \mathrm{O}$ can be calculated, thus $\mathrm{ML}_{\mathrm{H} 2 \mathrm{O}-400-500}$ can be obtained from Equation 2. Table 3 shows the calculated results of $\mathrm{ML}_{\mathrm{H} 2 \mathrm{O}-400-500}$ and $\mathrm{ML}_{\mathrm{CO} 2-400-500}$ for the fraction 0/0.63mm. As can be seen, the mass ratio of $\mathrm{CO}_{2}$ in $\mathrm{ML}_{400-500}$ changes as the carbonation degree changes. For laboratory manufactured noncarbonated RCA (RCAl_nc), ML400-500 is totally from the bounded water by portlandite. 
For laboratory manufactured well carbonated RCA (RCAl_wc), MLCO2-400-500 contains $92 \%$ in the $\mathrm{ML}_{400-}$ 500. For industrial RCA, ML $\mathrm{CO}_{\mathrm{CO}-400-500}$ contains $26 \%$ for RCAi. As a consequence, the portlandite content of industrial RCA is between the zone of noncarbonated RCA and well carbonated RCA.

$$
M L_{\mathrm{H} 2 \mathrm{O}-400-500}=M L_{400-500} \times \frac{18 \times S_{\mathrm{H}_{2} \mathrm{O}}}{44 \times S_{\mathrm{CO}_{2}}+18 \times S_{\mathrm{H}_{2} \mathrm{O}}}
$$

Table 2. Mass loss based TGA with gas for all studied RCA

\begin{tabular}{|c|c|c|c|c|c|}
\hline & ML $105-400$ & ML400-500 & ML500-600 & ML600-700 & ML700-1095 \\
\hline RCAl_nc 0/0.63 & 2.04 & 1.04 & 0.35 & 1.59 & 29.33 \\
\hline RCAl_nc 0.63/1.25 & 1.81 & 1.02 & 0.32 & 1.37 & 29.99 \\
\hline RCAl_nc 1.25/2.5 & 1.53 & 1.01 & 0.3 & 1.22 & 30.85 \\
\hline RCA1_nc 2.5/5 & 1.44 & 0.98 & 0.29 & 1.21 & 31.25 \\
\hline RCAl_wc 0/0.63 & 1.03 & 0.88 & 2.91 & 3.54 & 29.39 \\
\hline RCAl_wc 0.63/1.25 & 0.94 & 0.8 & 2.54 & 3.11 & 30.74 \\
\hline RCAl_wc 1.25/2.5 & 0.81 & 0.69 & 2.23 & 2.8 & 31.63 \\
\hline RCAl_wc 2.5/5 & 0.68 & 0.6 & 1.92 & 2.49 & 32.58 \\
\hline RCAi 0/0.63 & 1.98 & 0.64 & 0.72 & 1.92 & 13.11 \\
\hline RCAi 0.63/1.25 & 1.68 & 0.55 & 0.57 & 1.5 & 17.19 \\
\hline RCAi 1.25/2.5 & 1.48 & 0.5 & 0.52 & 1.37 & 18.63 \\
\hline RCAi 2.5/5 & 1.34 & 0.47 & 0.73 & 1.62 & 19.28 \\
\hline
\end{tabular}

Table 3. MLH2O-400-500 and MLCO2-400-500 based on TGA with gas

\begin{tabular}{|c|c|c|c|c|c|}
\hline & $\mathrm{S}_{\mathrm{H} 2 \mathrm{O}}$ & $\mathrm{S}_{\mathrm{CO} 2}$ & ML400-500 & ML $_{\text {H2O-400-500 }}$ & MLCO2-400-500 \\
\hline RCAl_nc 0/0.63 & 0.50 & 0 & 1.04 & 1.04 & 0 \\
\hline RCAl_wc 0/0.63 & 0.03 & 0.12 & 0.88 & 0.07 & 0.81 \\
\hline RCAi 0/0.63 & 0.42 & 0.06 & 0.64 & 0.47 & 0.17 \\
\hline
\end{tabular}

Density. Figure 6 presents the variation of density measured with the helium pycnometer as a function of granular class. It shows that the density of RCA increases as the average particle size increases for all studied RCA. The density of all fractions of RCAl_wc is larger than that of RCAl_nc. This is due to transfer of portlandite to calcite; indeed calcite has larger density than portlandite. After carbonation, the slope of density to average particle size of RCAl_wc is lower than that of RCAl_nc, it can be explained by the fact that the finer fraction of RCA has higher hardened cement paste content, and the density of the latter increased by the carbonation. The density of all the fractions of industrial RCA is larger than that of RCAl_nc. The larger values of density are obtained for the industrial RCA could be due to the carbonation, however, the composition of RCA, the density of natural aggregate and density of cement paste in RCA could also change the density of industrial RCA, which are not known for industrial RCA. 


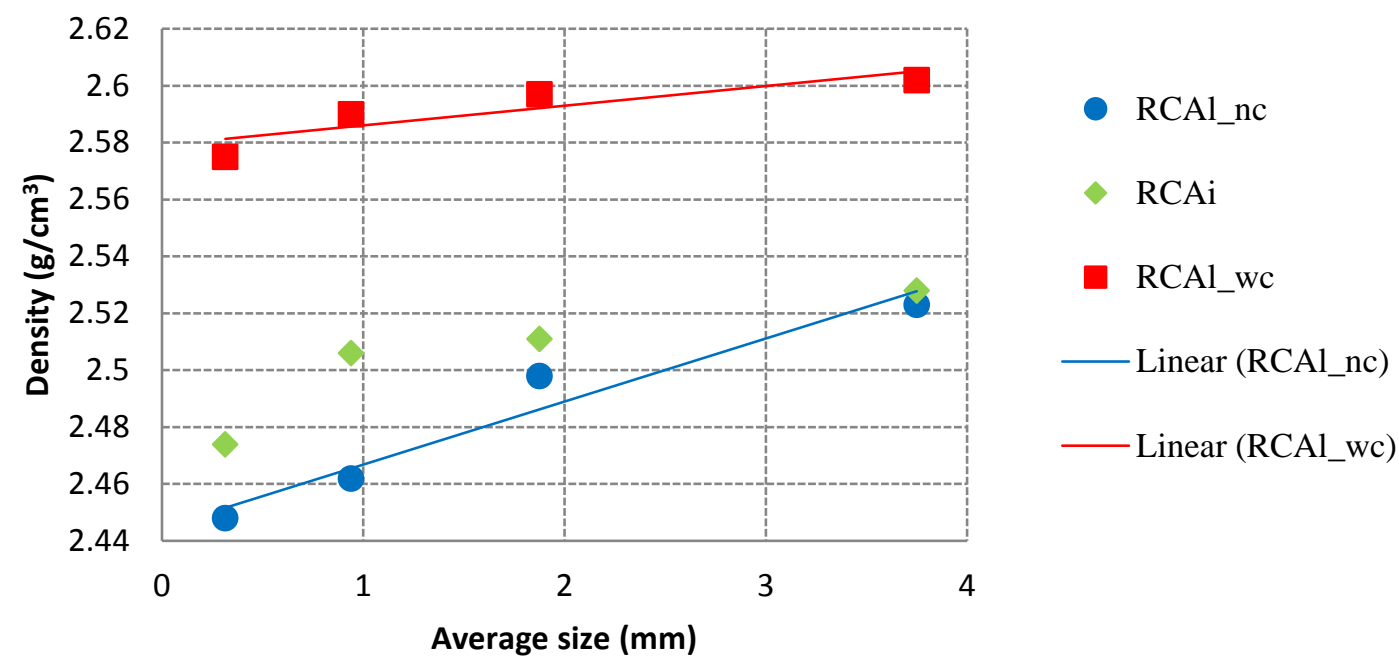

Figure 6. Density of all studied RCA as a function of the average size of the four different granular classes considered $(0 / 0.63,0.63 / 1.25,1.25 / 2.5,2.5 / 5 \mathrm{~mm})$

Water absorption and porosity. Figure 7 shows the water absorption coefficients of the four granular fractions of RCAl_nc and RCAl_wc measured with the IFSTTAR method. The water absorption coefficients obtained with all the granular classes of RCAl_wc are significantly lower than those obtained with RCAl_nc. It can be attributed to the reduction of cement paste porosity due to carbonation. After the carbonantion, the water absorption of RCA decrease $32.8 \%, 30.9 \%, 31.1 \%, 25.8 \%$ for the fraction $2.5 / 5 \mathrm{~mm}, 1.25 / 2.5 \mathrm{~mm}, 0.63 / 1.25 \mathrm{~mm}, 0 / 0.63 \mathrm{~mm}$ respectively, which is also reported by Grabiec [Garbiec et al. 2012] .

The MIP results of RCAl_nc and RCAl_wc show that the porosity of RCA decreases after the carbonation from $14.1 \%$ to $7.8 \%$, the transformation of portlandite to calcite and the formation of amorphous carbonation products during accelerated carbonation tests reduce the porosity of hardened cement paste, which leads to the reduction of water absorption of RCA after the accelerated carbonation.

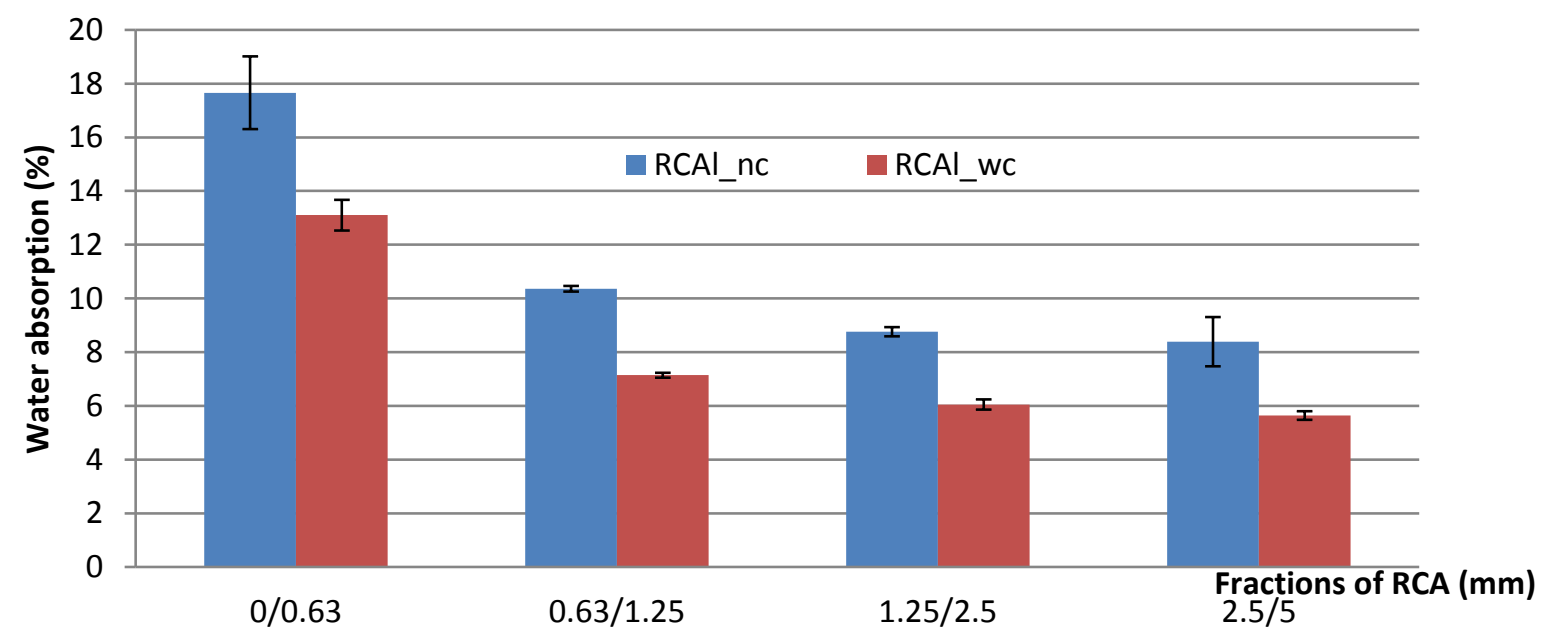

Figure 7. Water absorption of RCAI_nc and RCAl_wc measured by IFSTTAR method 


\section{CONCLUSION}

The possibility of improving the properties of RCA by accelerated carbonation has been studied. Laboratory manufactured noncarbonated RCA (RCAl_nc) and laboratory manufactured well carbonated RCA (RCAl_wc), together with industrial RCA (RCAi) have been tested for mass loss measured by themogravimetric analysis, density, porosity and water absorption. Main conclusions obtained are as follows:

- The finer fraction of RCA contains higher quantity of portlandite, and the finer fraction of RCA has larger hardened cement paste content and also higher porosity comparing with the coarser fraction of RCA. After accelerated carbonation, $\mathrm{ML}_{400-500}$ decreases which is due to the transfer of portlandite to calcite leading to a lesser loss of water. In the same time, $\mathrm{ML}_{500-600}$ and $\mathrm{ML}_{600-700}$ increases after carbonation due to a significant departure of $\mathrm{CO}_{2}$ between 500 and $700^{\circ} \mathrm{C}$. The formation of amorphous carbonation products occurred during the accelerated carbonation tests. The portlandite content of industrial RCA is between the zone of noncarbonated RCA and well carbonated RCA.

- The density of all the fractions of RCAl_wc is larger than that of RCAl_nc. This is due to transfer of portlandite to calcite; indeed calcite has larger density than portlandite.

- The water absorption coefficients obtained with all the granular classes of RCAl_wc are significantly lower than those obtained with RCAl_nc. It can be attributed to the reduction of hardened cement paste porosity due to carbonation (confirmed by the MIP results). After the carbonation, the water absorption of RCA decrease $32.8 \%, 30.9 \%, 31.1 \%, 25.8 \%$ for the fraction $2.5 / 5 \mathrm{~mm}, 1.25 / 2.5 \mathrm{~mm}$, $0.63 / 1.25 \mathrm{~mm}, 0 / 0.63 \mathrm{~mm}$ respectively.

\section{ACKNOWLEDGEMENT}

Authors would like to thank Lafarge Company for supply of cement and the Holcim Company for supply of natural aggregates. Authors would also like to thank Colas Company for the supply of recycled concrete aggregates. Authors would also like to thank China Scholarship Council (CSC) for its financial support. Finally, authors would like to thank the Government of Wallonia DGO6 for financial support through the project Beware Academia CONRePaD (Design of concrete with recycled concrete aggregates by means of Packing Density Method).

\section{REFERENCES}

Alarcon-Ruiz L, Platret G, Massieu E, Ehrlacher A. (2005) "The use of thermal analysis in assessing the effect of temperature on a cement paste." Cement and Concrete Research, 35(3), 609-613.

Chang C-F, Chen J-W. (2006) "The experimental investigation of concrete carbonation depth." Cement and Concrete Research. 36(9), 1760-1767.

Courard L., Michel F., Delhez P. (2010) "Use of Concrete Road Recycled Aggregates for Roller Compacted Concrete." Construction Building Material, 24(3), 390-395.

DeJong MJ, Ulm F-J. (2007). "The nanogranular behavior of CSH at elevated temperatures (up to 700 C)." Cement and Concrete Research, 37(1), 1-12.

Grabiec AM, Klama J, Zawal D, Krupa D. (2012) "Modification of recycled concrete aggregate by calcium carbonate biodeposition." Construction and Building Materials, 34, 145-150.

IFSTTAR. (2011) "Test $\mathrm{N}^{\circ}$ 78. Tests on granulats in concrte: measurment of total water absorption of crushed sand." 
Ngala V, Page C. (1997) "Effects of carbonation on pore structure and diffusional properties of hydrated cement pastes." Cement and Concrete Research, 27(7), 995-1007.

Poon CS, Kou SC, Lam L. (2002) "Use of recycled aggregates in molded concrete bricks and blocks." Construction and Building Materials, 16(5), 281-289.

Zhao Z., Rémond S., Damidot D., Xu W. (2013) "Influence of hardened cement paste content on the water absorption of fine recycled concrete aggregates." Journal of Sustainable Cement-Based Materials, 2, 186-203.

Zhao Z., Rémond S., Damidot D., Xu W. (2015) "Influence of fine recycled concrete aggregates on the properties of mortars." Construction and Building Materials, 81, 179-186. 